\title{
Power System Stability Improvement of Ghana's Generation and Transmission System Using FACTS Devices
}

\author{
Lawrence Aikins ${ }^{1}$, Christian Kwaku Amuzuvi ${ }^{2,}$, \\ ${ }^{1}$ Engineering and Maintenance Department, Takoradi Thermal Power Plant 2, Takoradi, Ghana \\ ${ }^{2}$ Department of Renewable Energy Engineering, University of Mines and Technology, Tarkwa, Ghana
}

Email address:

Lawrence.Aikins@taqaglobal.com (L. Aikins),ckamuzuvi@umat.edu.gh (C. K. Amuzuvi)

${ }^{*}$ Corresponding author

\section{To cite this article:}

Lawrence Aikins, Christian Kwaku Amuzuvi. Power System Stability Improvement of Ghana's Generation and Transmission System Using FACTS Devices. Journal of Electrical and Electronic Engineering. Vol. 8, No. 2, 2020, pp. 47-63. doi: 10.11648/j.jeee.20200802.12

Received: May 5, 2020; Accepted: June 9, 2020; Published: June 20, 2020

\begin{abstract}
Power system stability is a major challenge in the secured operation of today's interconnected power systems. Voltage stability as a branch of power system stability, is a major problem facing power systems in Ghana. The power system is subjected to major blackouts or collapses due to voltage instability. It is manifested by several distinguishing features: low system voltage profiles, heavy reactive line flows, inadequate reactive support, and heavily loaded power systems. Voltage stability depends on the ability of a power system to maintain acceptable voltage for system buses under normal conditions, and system disturbances. This paper evaluates the steady-state voltage stability of the power system through modelling and simulation using the Power System Simulator for Engineering power system analysis software and the results validated with MATPOWER. Load flow simulations using the Newton Raphson method under steady-state base load condition with and without contingencies were done. Simulation results revealed under normal, and contingency cases show the power system has voltage profile, that violates the voltage stability constraint of between $0.95 \mathrm{pu}$ and $1.05 \mathrm{pu}$ for normal system voltage, high transmission system losses and heavy congestion. The Flexible Alternative Current Transmission System (FACTS) devices was used to improve the power system stability. Three types of FACTS devices: SVC, STATCOM, and TCSC are selected and optimally placed in the power system to improve voltage stability. Generic algorithm as artificial intelligence-based method was used in MATLAB environment to optimally size and locate five (5) FACTS devices; one (1) STATCOM and four (4) SVC in the power system. The algorithm was found to be reliable as it yielded good results by the improvement in voltage stability and decreasing the transmission line active and reactive power losses significantly.
\end{abstract}

Keywords: Flexible Alternative Current Transmission System, Genetic Algorithm, Voltage Stability

\section{Introduction}

The introduction of Ghana's power sector reforms about a decade ago have seen the functions of power generation and transmission delegated to two companies namely: the Volta River Authority (VRA) and the Ghana Grid Company Limited (GRIDCo) respectively. The liberalisation and deregulation of the industry and the introduction of the grid code in line with the reforms poses a great challenge to utilities in the generation, transmission and distribution sectors. The power system must have adequate security margins to reduce the vulnerability to transient instability, dynamic instability and voltage instability problems.
The current increase in electrical energy demand due to current modern lifestyles have made the world including Ghana to fully depend on power systems to propel industrial and economic growth. Presently, power demand has increased substantially with annual growth rates of $8.6 \%$ and $7.6 \%$ for peak power demand and energy consumption, respectively.

FACTS technology is essential in alleviating some of the difficulties by enabling utilities get reliable service from the transmission facilities and enhance the power system stability. With the relatively low investment compared with new transmission and generation facilities, FACTS technology allows for better utilisation of the existing transmission and generation facilities. 


\subsection{Overview of Ghana's Generation and Transmission System}

The grid code provides strict constraints on voltage, frequency, and loading limitations for operators within the power industry to meet. The states of the various power systems operating as specified in the grid code is shown in Table 1. Power system stability, security, reliability, and quality remains crucial to the progress of economic transformation in Ghana. The power system is presently burdened with instability problems (both voltage and frequency instability) resulting in power swings, disturbances, and oscillations, which sometimes leads to partial or total system collapse. The system is subjected to major blackouts or collapses with a total of 11 (eleven) disturbances under different forms of instability from the year 2012 to 2014. Out of the 11 disturbances, 9 were partial and 2 total system collapse.

Table 1. States of the Power Systems Operating as Specified in Ghana Grid Code.

\begin{tabular}{|c|c|c|c|}
\hline $\begin{array}{l}\text { Power System } \\
\text { Operating States }\end{array}$ & Frequency Limits & Voltage Limits & Loading Limits \\
\hline Normal State & $\begin{array}{l}\text { Within the limits of } 49.8 \mathrm{~Hz} \text { and } \\
50.2 \mathrm{~Hz}\end{array}$ & $\begin{array}{l}\text { Within the limits of } \pm 5 \% \text { of the } \\
\text { nominal value }\end{array}$ & $\begin{array}{l}\text { Loading levels of all transmission circuits and substation } \\
\text { equipment are below } 85 \% \text { of their continuous rating }\end{array}$ \\
\hline Alert State & $\begin{array}{l}\text { Outside the limits of Normal } \\
\text { state, but within } 49.0 \mathrm{~Hz} \text { and } \\
51.0 \mathrm{~Hz}\end{array}$ & $\begin{array}{l}\text { Outside the limits of } \pm 5 \% \text { of the } \\
\text { nominal value but within the limits } \\
\text { of } \pm 10 \% \text { of the nominal voltage }\end{array}$ & $\begin{array}{l}\text { There is critical loading or imminent overloading of } \\
\text { transmission lines or substations }\end{array}$ \\
\hline Emergency State & $\begin{array}{l}\text { There is generation deficiency } \\
\text { and frequency is outside the } \\
49.0 \mathrm{~Hz} \text { and } 51.0 \mathrm{~Hz}\end{array}$ & $\begin{array}{l}\text { Outside the limits of } \pm 10 \% \text { of the } \\
\text { nominal value }\end{array}$ & $\begin{array}{l}\text { The loading level of any transmission circuit or substation } \\
\text { equipment is above } 110 \% \text { of its continuous rating }\end{array}$ \\
\hline
\end{tabular}

(Source: Energy Commission, Ghana Grid Code, 2009)

System collapse is on the increase resulting in insecurity and unreliability of the entire power system. The inconvenience and economic cost it brings on both domestic and industrial consumers is high and intolerable. The causes attributed to the collapses are faulty, obsolete equipment, overloading of the power plant generators, and transmission networks, which leads to tripping of the generators. Power system stability can be classified into three areas: rotor angle stability, frequency stability, and voltage stability [1]. Voltage stability is a major and critical concern in power systems. Voltage instability, however, contributes to system collapse or blackouts. The cause of voltage instability is the drop in reactive power at various locations in the interconnected power system.

Table 2. Ghana's Power Generation Capacity as at May 2014.

\begin{tabular}{|c|c|c|c|c|}
\hline \multirow{2}{*}{ GENERATION PLANT } & \multicolumn{2}{|c|}{ CAPACITY (MW) } & \multirow{2}{*}{ Plant Utilisation Factor } & \multirow{2}{*}{ Expected Energy (GWh) } \\
\hline & Installed & Dependable & & \\
\hline Hydro Power Plants & & & & \\
\hline Akosombo & 1020.0 & 960.0 & 0.90 & $6,643.20$ \\
\hline Kpong & 160.0 & 140.0 & 0.90 & $1,140.55$ \\
\hline Bui & 400.0 & 380.0 & 0.30 & 998.64 \\
\hline Sub-Total & $1,580.0$ & $1,480.0$ & & $8,784.39$ \\
\hline Thermal Power Plants & & & & \\
\hline TAPCO (CC) & 330.0 & 300.0 & 0.70 & $1,839.60$ \\
\hline TICO (SC) & 220.0 & 200.0 & 0.10 & 175.20 \\
\hline Sunon Asogli (Gas) & 200.0 & 180.0 & 0.75 & $1,182.60$ \\
\hline Tema Thermal Plant 1 - TT1PP & 126.0 & 110.0 & 0.70 & 674.52 \\
\hline Tema Thermal Plant 2- TT2PP & 49.5 & 45.0 & 0.70 & 275.94 \\
\hline Takoradi 3 (T3) & 132.0 & 120.0 & 0.10 & 105.12 \\
\hline Mines Reserve Plant (MRP) & 80.0 & 40.0 & 0.75 & 245.28 \\
\hline CENIT Energy Ltd. & 126.0 & 110.0 & 0.70 & 674.52 \\
\hline Sub-Total & $1,263.5$ & $1,105.0$ & & $5,172.78$ \\
\hline Renewables \& Embedded Generation & & & & \\
\hline Genser Power & 5.0 & 2.0 & 0.70 & 12.26 \\
\hline VRA Solar grid-inter-tied & 2.5 & 2.0 & 0.30 & 5.26 \\
\hline Sub-Total & 7.5 & 4.0 & & 17.52 \\
\hline $\begin{array}{l}\text { Total } \\
\text { (Source: Energy Commission, 2014) }\end{array}$ & $2,851.5$ & 2,589 & & $\approx 13,973$ \\
\hline
\end{tabular}

\subsection{Generation System}

The electric power generation sector in Ghana is dominated by a state-controlled monopoly. Power sector reforms have allowed the penetration of independent power producers (IPPs) in the generation category, and have underscored the commitment of the private sector to tackle the issue of adequacy, security, and reliability of supply. The area of focus of the IPPs is towards thermal power generation, which is configured as either a simple cycle gas turbine units or combined cycle power plant (CCPP).

Currently, Ghana depends on two primary types of generation facilities; hydroelectric plants and thermal plants. 
The current installed power generation capacity as at May, 2014 including IPPs is 2851 MW of which, $56 \%$ is hydro, and $44 \%$ is thermal. The dependable power generation capacity at the same time is $2589 \mathrm{MW}$, of which, $57 \%$ is hydro, and $43 \%$ thermal. Table 2 list the current generating stations and their capacities.

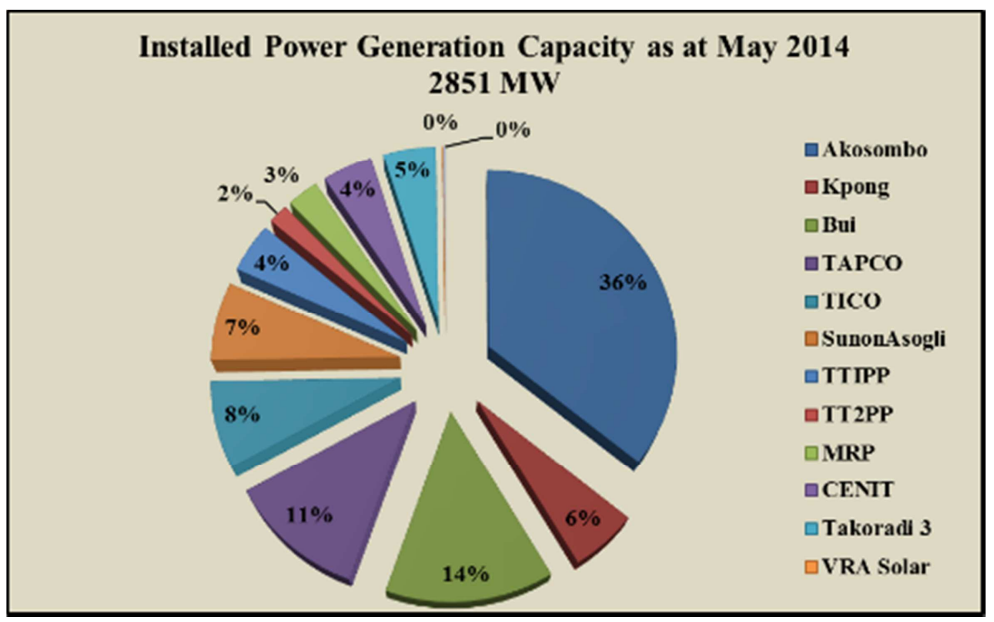

(a)

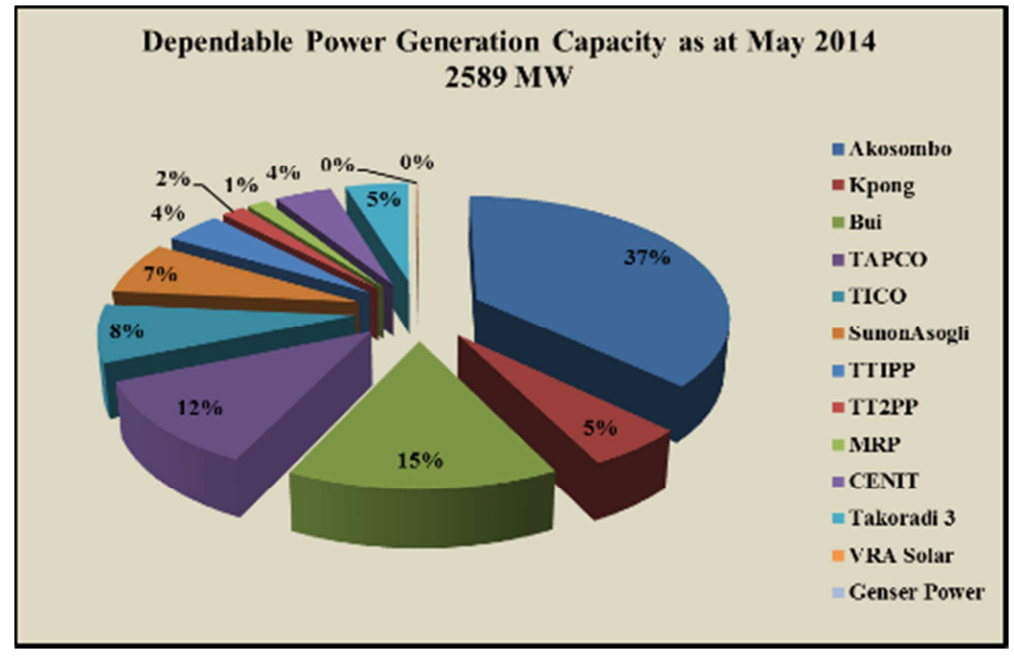

(b)

Figure 1. (a) Percentage of Installed Capacities as against the total installed Power Generation; and (b) Percentage of Dependable Capacities as against the total installed Power Generation.

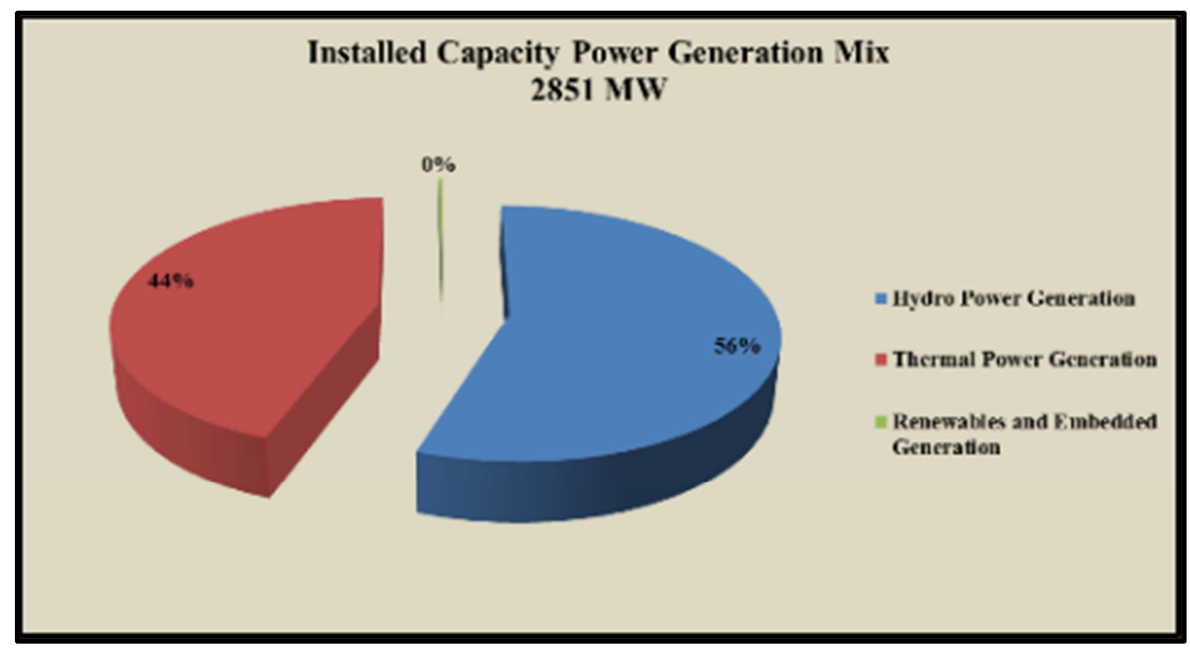




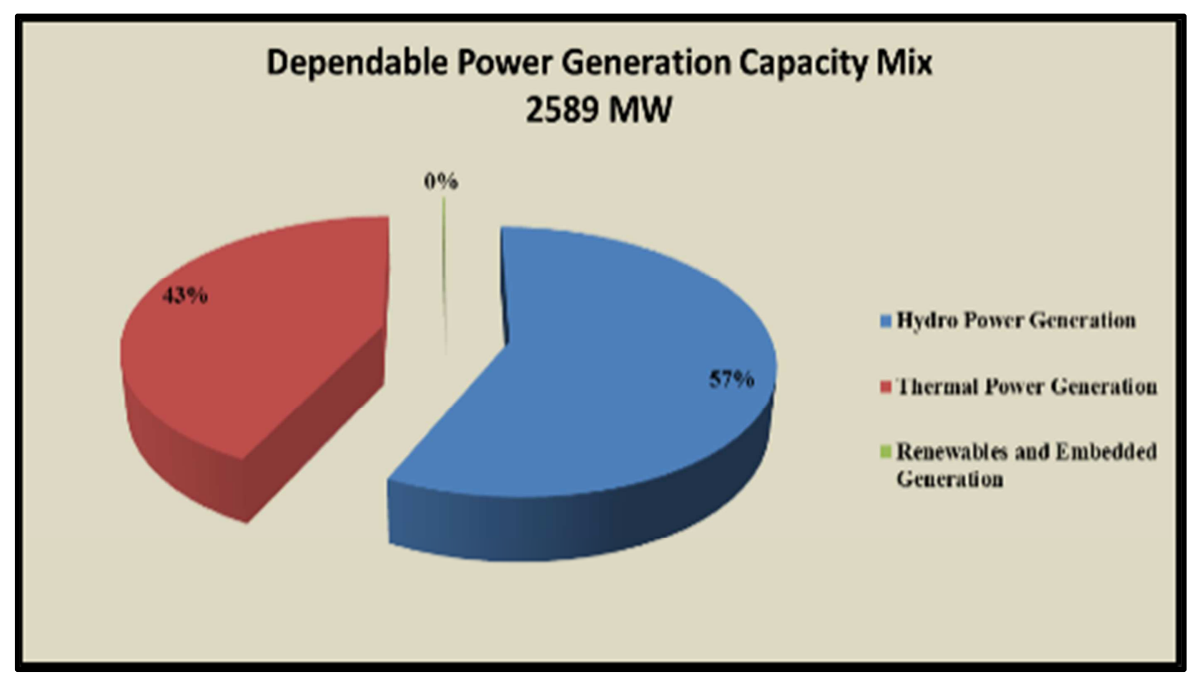

(b)

Figure 2. (a) Percentages of Installed Capacity of Thermal Power and Hydro Power Generation; and (b) Percentages of Dependable Capacity of Thermal Power and Hydro Power Generation.

Figure 1 (a) and (b) provide the percentage contributions of the generating stations towards the installed and dependable capacity, respectively. Figure 2 (a) and (b) also highlights the installed and dependable capacity generation mix for hydro and thermal power. TAPCO is Takoradi Power Company, a combined cycle (CC) thermal plant; TICO is Takoradi International Power Company, a simple cycle (SC) thermal plant as shown in Table 3.
Considering the latest demand and rate of growth forecasts from the year 2014 to 2023 as indicated in Table 3, there is significant increase in demand from the year 2017. Over the next five years, seven (7) additional generation projects are scheduled to begin commercial operation, potentially adding up to $1269 \mathrm{MW}$ of nameplate generation capacity to the grid (Table 3).

Table 3. Generation capacity additions from the year 2015-2020.

\begin{tabular}{lllll}
\hline Unit Name & Owner/Operator & Generation Type & Proposed Online Date & Nameplate Capacity (MW) \\
\hline TICO (Steam Component) & TICO & Thermal & 2015 & 110 \\
Kpone Power Plant & VRA & Thermal & 2015 & 200 \\
Osagyefo Power Barge & GOG & Thermal & 2016 & 125 \\
CENPOWER & CENPOWER & Thermal & 2017 & 350 \\
Takoradi 4 & VRA & Thermal & 2017 & 132 \\
TTIPP\& CENIT (Steam Component) & VRA & Thermal & 2019 & 2020 \\
Domunli Plant & VRA & Thermal & 220 & 110 \\
Total Thermal & & & & 1269 \\
\hline
\end{tabular}

\subsection{Transmission System}

The transmission system involves a network of substations and transmission lines that connect generation sources to load centres and allows the wholesale power system to transport power from generation resources to bulk consumers. The generation stations linking the transmission system are strategically located close to the major load centres. Table 4 provides an overview of transmission network in Ghana.

Table 4. Fact Sheet on the Transmission Network in Ghana.

\begin{tabular}{ll}
\hline Transmission Line & Length $(\mathbf{k m})$ \\
\hline 330 kV Line & 219.5 \\
161 kV Line & 3888.1 \\
225 kV Line & 73.4 \\
69 kV Line & 132.8 \\
Total Transmission Line Length & 4313.8 \\
Number of Transformers including spares & 100 \\
Transformer Capacity & 2915 MVA \\
Number of Transformer/Switching Substations & 53 \\
\hline
\end{tabular}

\begin{tabular}{ll}
\hline Transmission Line & Length $(\mathbf{k m})$ \\
\hline Largest Switching Substation is Volta & Tema \\
& $330 / 161 \mathrm{kV} 161 / 69$ \\
Transformer Substation Voltages & $\mathrm{kV} 161 / 34.5 \mathrm{kV}$ \\
& $161 / 11.5 \mathrm{kV}$ Stations \\
\hline
\end{tabular}

(Source: GRIDCo, 2014)

The network consists of about 4,000 kilometres of 161 $\mathrm{kV}$ high voltage transmission lines, 220 kilometres of 330 $\mathrm{kV}$ transmission lines, 73 kilometres of $225 \mathrm{kV}$ transmission lines, and 132 kilometres of $69 \mathrm{kV}$ transmission lines. The on-going implementation of a series of $330 \mathrm{kV}$ transmission projects will result in $330 \mathrm{kV}$ replacing $161 \mathrm{kV}$ as the primary backbone transmission voltage. The transmission lines are connected to 53 primary substations with a combined installed transformer capacity of 2,915 MVA. At the substations, voltage is reduced to $34.5 \mathrm{kV}, 11.5 \mathrm{kV}, 6.6 \mathrm{kV}$, etc. for supply to bulk supply customers. 


\subsection{Power System Stability}

Power system stability is a critical issue in the operation of interconnected power systems, and has been identified since the 1920s [2]. As power systems have advanced through continuing growth in regional interconnections, use of new technologies in power electronics and controls, and the increased operation in highly stressed conditions, different forms of system instability have emerged.

Transient instability has been the dominant stability problem on most power systems, and has been the focus of much of the industry's attention regarding system stability. At present, voltage stability, frequency stability and inter area oscillations have become greater concerns than in the past. The proper understanding of the different forms of instability and how they are interrelated is essential for the satisfactory design and operation of the power system [1]. Power systems rely on synchronous machines for the generation of electrical power and a necessary condition for satisfactory system operation is that, all synchronous machines remain in synchronism.

\subsection{Power System Stability Assessment}

Consideration is given to the assessment of voltage and rotor angle stability under the broad definition and classification of power system stability. The rotor angle stability is generally assessed using the swing equation [3] and the equal area criterion [4]. There are different voltage stability assessment tools or methods and they are broadly classified under two approaches: static and dynamic. Static voltage stability analysis, which is based on power flow solutions, is performed to identify the weak regions in terms of reactive power deficiency of the system and determine the critical contingencies and voltage stability margins for various power transfers within the power system. Dynamic voltage stability analysis, which is based on conducting time-domain simulations, is performed to assess the ability of the power system, with a significant share of rotating load [5]. A comprehensive voltage stability assessment would combine both static and dynamic analysis techniques [6]. Voltage stability analysis using static and dynamic methods in small radial network was performed [5].

\subsection{Flexible Alternative Current Transmission Systems}

The advancement of power electronics technologies and algorithms has improved the interconnection of power system using FACTS. FACTS principle is dependent on the advanced technologies of power electronic techniques and algorithms into a power system making it electronically controlled. The technology of FACTS has evolved over a period and brought to fruition during the 1980s at the Electric Power Research Institute (EPRI) [7]. Hingorani and Gyugi [8] had proposed the concept of FACTS devices in the EPRI. They showed the improvement of power system performance by using power electronic devices called FACTS devices. With low investment cost, FACTS technology allows for better utilisation of existing transmission and generation reserves, while enhancing the power system stability and performance.

The concept of FACTS refers to a family of power electronics-based devices able to enhance AC system controllability and stability and to increase power transfer capability. Edris et al. [9] as part of IEEE committee, proposed terms and definitions for different FACTS controllers. Accordingly, FACTS are defined by IEEE as "alternating current transmission systems incorporating power electronic-based and other static controllers to enhance controllability and increase power transfer capability". The benefits of FACTS are enormous and [10] summarised a number of benefits attributed to the use of FACTS in power systems: They include the following:

i. Dynamic voltage control: Its main selling point is to limit over-voltages over lightly loaded lines and cable systems, and prevent voltage depressions or collapses in heavily loaded or faulty systems;

ii. Increased power transmission capability and stability: Power networks can easily be stabilised without the need of installing new lines. This benefit is highly attractive because of cost reduction obtained from not installing new power lines. It also impacts on the environmental factors and restrictions placed on the complex expansion of networks; and

iii. Facilitation of renewable generation connection to the grid: Since FACTS has the characteristic of stability, renewable power generation could easily be connected to the grids with the aid of FACTS and thus fulfil the necessary grid code demands.

\subsubsection{FACTS Devices}

The idea of FACTS devices can be explained by the basic equation for $\mathrm{AC}$ power transmission. Power transmitted between two nodes of the system depends on the voltages at both ends of the interconnection, the impedance of the line, and the phase angle difference between both systems. Different FACTS devices can actively influence one or more of these parameters for power flow control and for improvement of voltage stability at the node of interconnection.

Kumar and Priya [11] explained that, there are two generations for realisation of power electronics-based FACTS controllers: the first generation employs conventional thyristor-switched capacitors, reactors, and quadrature tap-changing transformers. The second generation employs gate tum-off (GTO) thyristor-switched converters such as voltage source converters (VSCs). The first generation has resulted in the Static VAR Compensator (SVC), the Thyristor-Controlled Series Capacitor (TCSC), and the Thyristor-Controlled Phase Shifter Transformer (TCPST). The second generation has produced the Static Synchronous Compensator (STATCOM), the Static Synchronous Series Compensator (SSSC), the Unified Power Flow Controller (UPFC), and the Interline Power Flow Controller (IPFC). The two groups of FACTS controllers have distinctly different operating and performance characteristics.

The simplified models of SVC, TCVR, TCPST, TCSC, 
UPFC and STATCOM with energy storage superconducting magnetic energy storage (SMES) are shown in Figure 3 [12], [13].

Figure 4 provides the type of FACTS devices classified and categorised into mechanical switches, which are normally thyristor controlled, voltage source converter, and hybrid devices.
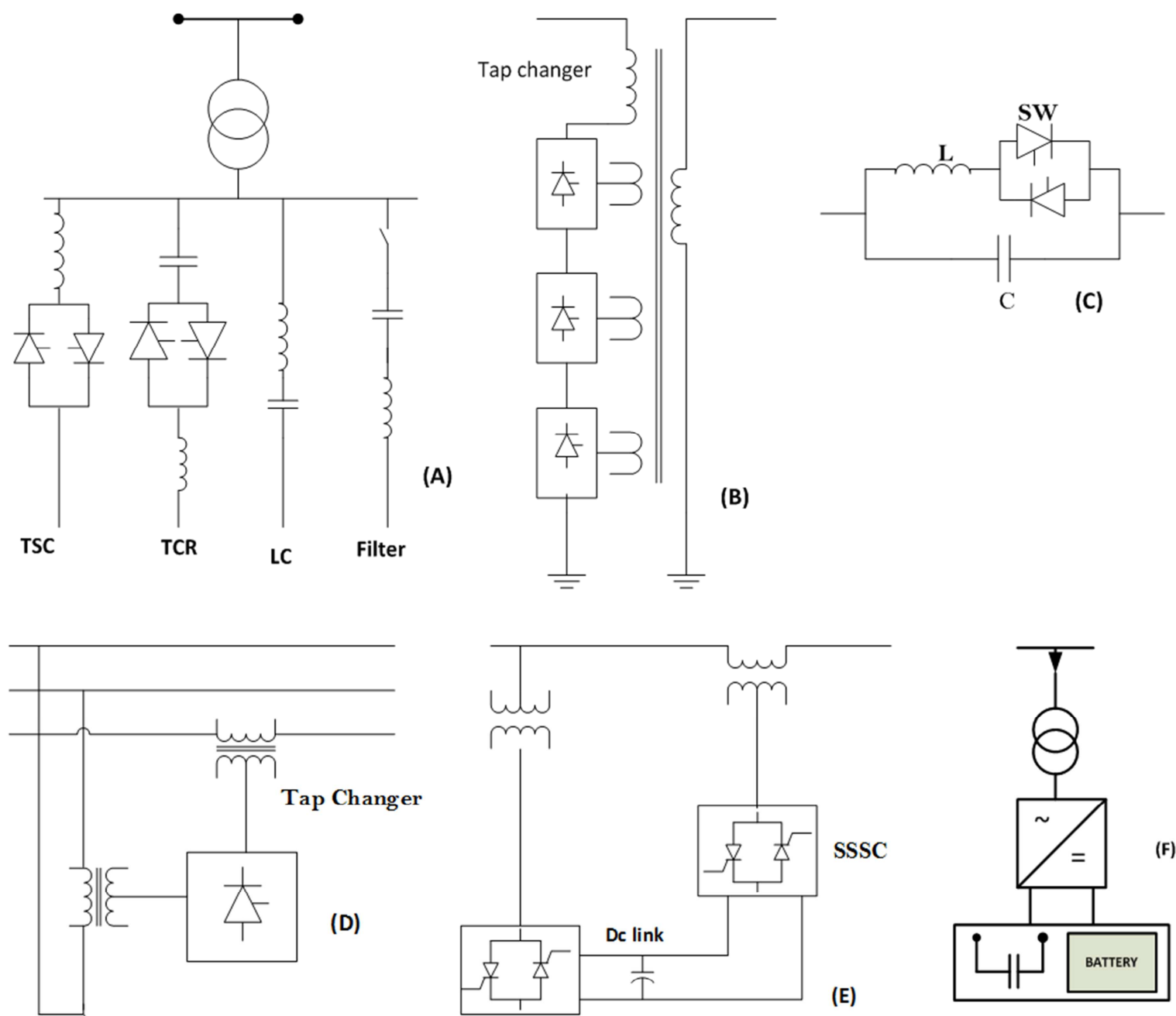

Sirjani et al. [14] carried out a comparison of the effectiveness of installing reactive power compensators, such as shunt capacitors, static VAR compensators (SVCs), and static synchronous compensators (STATCOMs) in a large-scale power networks for voltage profile improvement and voltage stability margin enhancement.

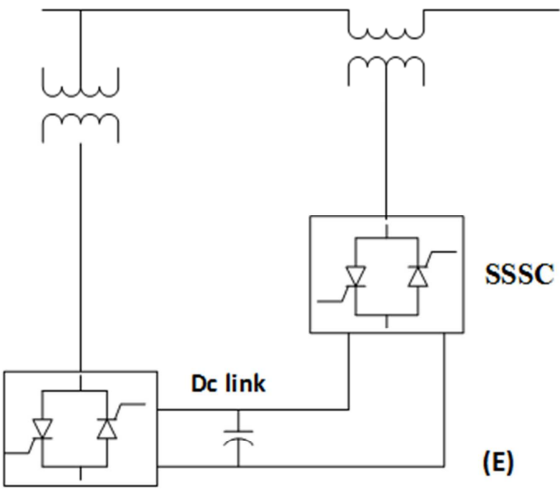

STATCOM

\section{(B)}

Figure 3. FACTS devices: (A) SVC; (B) TCVR; (C) TCSC; (D) TCPST; (E) UPFC; and (F) STATCOM with Energy Storage.

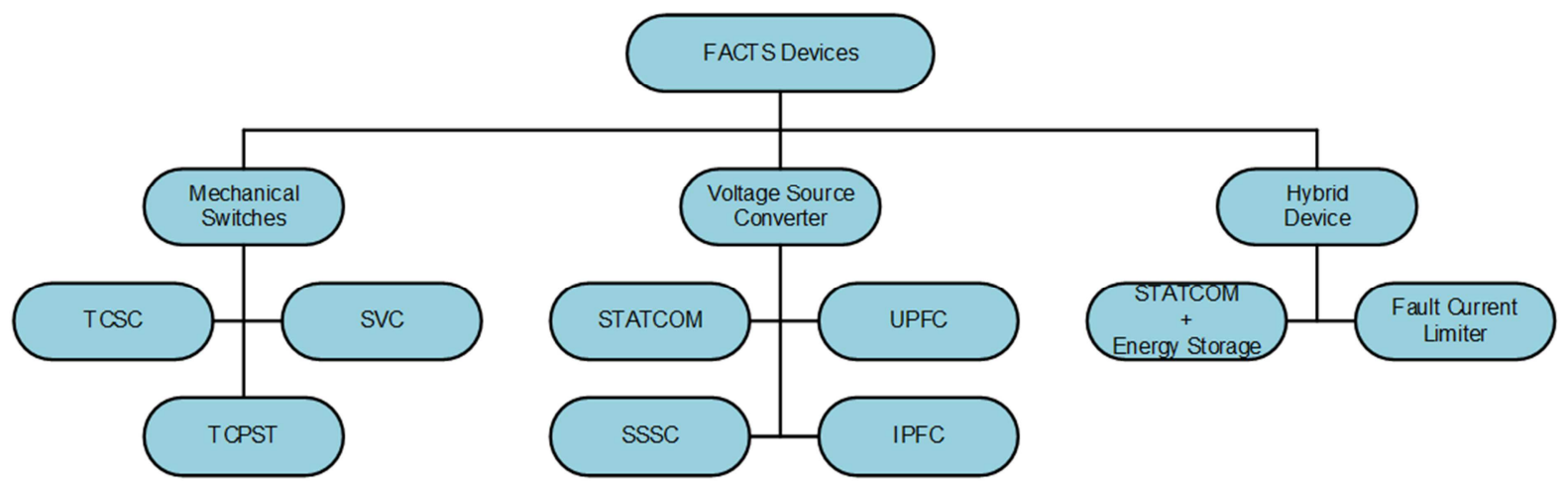

Figure 4. FACTS Devices Classification. 


\subsubsection{FACTS Installation Requirements}

In practical installation of FACTS in a power system, there are six common requirements as follows [15]:

i. What kinds of FACTS devices should be installed?

ii. Where in the system should be placed?

iii. How much capacity should it have?

iv. How to coordinate dynamically the interaction between multiple FACTS and the network to better exploit FACTS devices?

v. How to estimate economically the optimal size and number of FACTS to be installed in a practical network? and

vi. How to adjust dynamically the three-phase reactive power in unbalanced network?

\subsection{Optimal Placement of FACTS Devices}

The recent power sector restructuring and increased power demand has resulted in overloading of the transmission network, which has led to power system stability problems, more especially voltage stability. The process of mitigating the transmission line overloads and low system voltages, thereby, improving power system stability for all single contingencies is done by the optimal placement of FACTS devices. The effective placement of FACTS devices is very important for the rapid and successful operation of power systems.
In addition, FACTS placement is critical to ensure the utilisation of the full potential of the transmission network. The FACTS devices, such as, SVC, STATCOM, SSSC, TCSC, and UPFC as presented earlier, have their own advantages to control active and reactive power for static, dynamic voltage stability, and transient stability. To determine the optimal placement of FACTS devices to obtain the highest possible benefit from them, a suitable optimisation technique is used [16]. Sookananta et al. [17] provided the background of the placement of FACTS devices in modern electrical network.

Artificial Intelligence-Based Methods

The artificial intelligence-based methods for the optimal placement of FACTS devices are: Genetic Algorithm (GA), Expert System (ES), Artificial Neutral Network (ANN), Tabu Search (TS), Ant Colony Optimisation (ACO), Simulated Annealing (SA), Particle Swarm Optimisation (PSO), and Fuzzy logic (FL). The various artificial or computational intelligence methods with different techniques are grouped and presented in Figure 5 [18]. Among these techniques, the genetic algorithm and particle swarm optimisation are used for the optimal placement of FACTS devices in the power system for various objectives. They are: static voltage stability enhancement, violation avoidance of line thermal constraints, network loadability enhancement, power loss reduction, voltage profile improvement, dynamic stability improvement, and efficient damping of power swings [19].

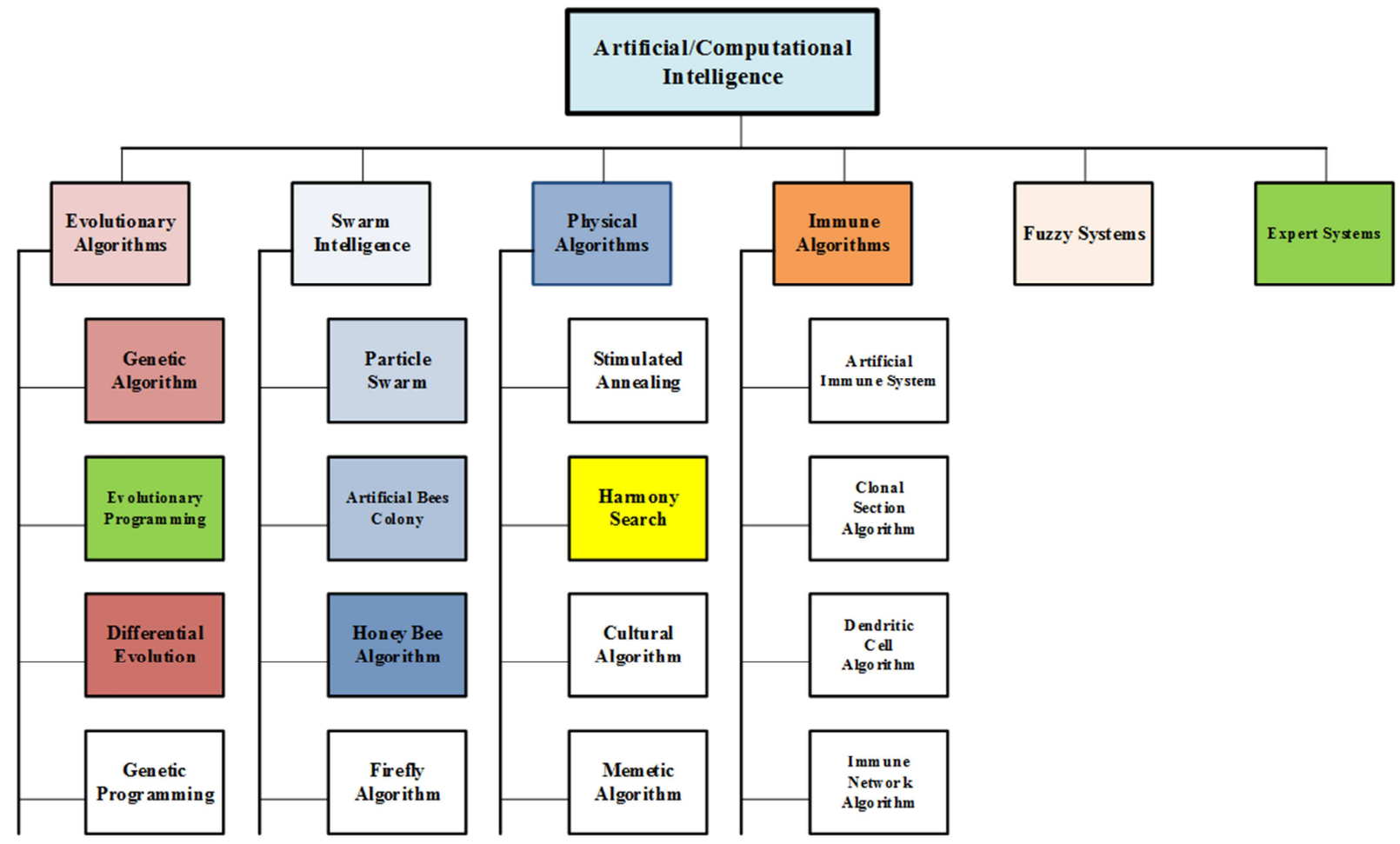

Figure 5. Artificial/Computational Intelligence categories with different methods.

\section{Materials and Methods}

The way of studying the power system operation is by modelling the system, and simulating its performance. To analyse, predict, and prescribe solutions to the power system stability problem, the modelling and simulation of the power system using the Siemens PTI Power System Simulator for 
Engineering (PSS®E) as the main software tool is described. The power system is made up of generators, transformers, buses, transmission lines, and loads. The power or load flow analysis of the power system is the fundamental step in the analysis of the power system. The data for the modelling of the power system equipment and simulation through power or load flow studies, were collected mainly from GRIDCo and VRA.

\subsection{Power System Simulator for Engineering (PSS/E)}

The Siemens PTI Power System Simulator (PSS $\AA E$ ) is composed of a comprehensive set of programs for studies of power system transmission network and generation performance in both steady-state and dynamic conditions (Siemens, 2013). PSS/E is a commercial software package for simulating, analysing, and optimising power system performance. It uses the Newton-Raphson (AC and DC) technique for regular power flow. Currently in PSS/E, two primary simulations are used, one for steady state analysis and one for dynamic simulation. PSS/E can be used to handle calculations for variety of analyses, including the following:

i. Power flow and related network functions;

ii. Contingency analysis;

iii. Optimal power flow;

iv. Fault analysis (balanced and unbalanced);

v. Network equivalent construction;

vi. Dynamic simulation; and

vii. Small signal stability analysis (NEVA).

Modelling of FACTS Devices in PSS/E

In this work, three FACTS devices have been selected for steady state modelling and optimal placement in the power system. They are: TCSC (Thyristor Controlled Series Capacitor), STATCOM (Static Synchronous Compensator), and SVC (Static VAR Compensator). The optimal FACTS placement strategy is done outside the PSS/E and MATLAB if genetic algorithm coding is used. The block diagrams of the selected FACTS devices in modelling are shown in Figures 6 and 7.

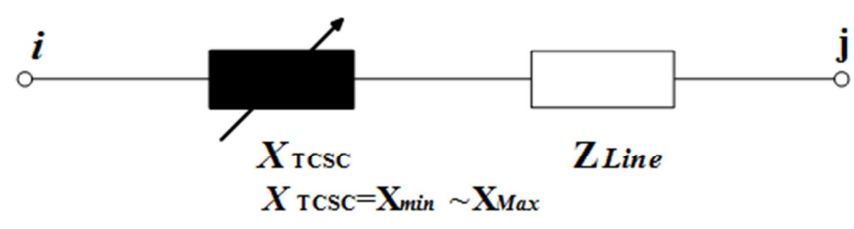

(a)

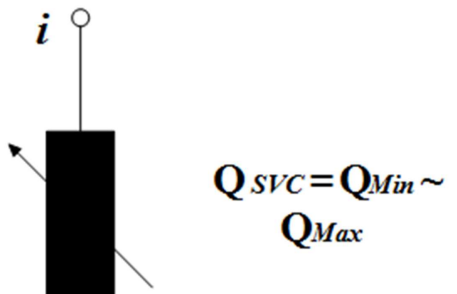

(b)

Figure 6. Block Diagram of the considered FACTS Devices in Power Flow: (a) TCSC; and (b) SVC.
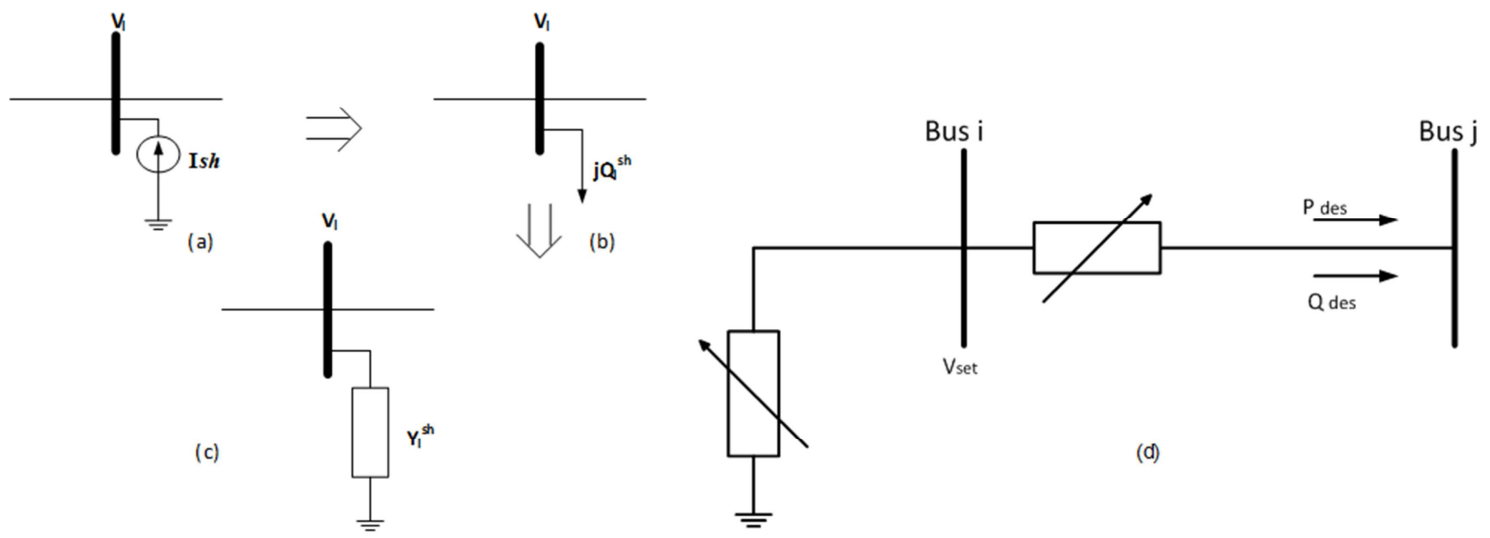

Figure 7. STATCOM Model: (a) Transformation from Current Injection; (b) to load injection; (c) Variable Susceptance; and (d) Basic FACTS Control Device Model in PSS/E.

\subsection{Implementation of $G A$ in MATPOWER/MATLAB program for optimal FACTS Allocation}

\subsubsection{FACTS Device Modelling using MATPOWER}

To use FACTS devices in the power system in MATPOWER/MATLAB environment, the FACTS devices must be modelled for the steady state power flow analysis. In this work, the steady state model of FACTS devices has been developed for the power flow studies. The models are implemented using MATPOWER 5.0b1 [20] and MATLAB 7.14 (2012A) for the GA optimal FACTS allocation. It is modelled simply to modify the reactance of transmission line. It may be inductive or capacitive, respectively, to decrease or increase the reactance of the transmission line. The reactance of TCSC is adjusted directly based on the reactance of the transmission line. The working range of TCSC is between $-0.7 \mathrm{XL}$ and $0.2 \mathrm{XL}$, where $\mathrm{XL}$ is the transmission line reactance. The SVC is a shunt connected static VAR generator 
or absorber. The SVC is used to control the reactive power compensation of the power system at a nominal voltage of 1 pu. In this study, it is modelled as an ideal reactive power injection at Bus i (Figure 7 (d)), where it is connected. The working range of SVC is between -100 MVAr and $100 \mathrm{MVAr}$. The steady state of STATCOM is also modelled to inject reactive power at the Bus $\mathrm{j}$ (Figure 7 (d)), where it is connected. The working range of STATCOM is also between $-100 \mathrm{MVAr}$ and $100 \mathrm{MVAr}$.

\subsubsection{GA FACTS Devices Optimisation Problem Formulation}

GA is one of the Evolutionary Algorithms search technique based on the mechanism of natural selection and genetics. They can search several possible solutions simultaneously and produces high quality solutions. The goal of the optimisation is to determine the optimal rating and location of the FACTS devices. For implementing the GA optimisation with FACTS devices, two main aspects are considered in the formulation of the problem. They are the identification of the objective function for the optimisation, and the characterisation of the set of feasible solutions (constraints definition).

In this paper, two goals are to be accomplished:

i. Minimise the voltage deviations at all the buses in the system within the voltage stability constraints; and

ii. Minimise the active power losses of the transmission lines.

Thus, two objective functions $F 1$ and $F 2$ are defined as in (1) and (2):

$$
F_{1}=\sqrt{\sum_{i=1}^{N b u s}\left(V_{i}-1\right)^{2}}
$$

where:

$F_{1}$ is the voltage deviation objective function;

$\mathrm{V}_{\mathrm{i}}$ is the value of the voltage at bus $\mathrm{i}$ in $\mathrm{pu}$; and

$\mathrm{N}_{\text {bus }}$ is the total number of buses in the power system.

$$
F_{2}=\sum_{k=1}^{N t l} P L_{t l}
$$

where:

$\mathrm{F}_{2}$ is the objective function to minimise the active power losses;

$\mathrm{PL}_{\mathrm{tl}}$ is the active power loss in the $\mathrm{tl}^{\text {th }}$ line; and

$\mathrm{N}_{\mathrm{tl}}$ is the number of transmission lines in the system.

The multi-objective optimisation problem is determined using the weighted sum of both objective functions, F1, and $\mathrm{F} 2$, to create one objective function $\mathrm{F}$. The best solution is the one for which $\mathrm{F}$ is a minimum.

$$
F=\omega_{1} * F_{1}+\omega_{2} * F_{2}
$$

The weight that multiplies each objective function is adjusted to reflect the relative importance that each goal has, with respect to the other. In this work, since the main aim is to enhance the voltage stability, the voltage deviation is of more importance than the active power loss. Hence, the values of $\omega_{1}$ and $\omega_{2}$ are 0.7 and 0.3 respectively and the sum of $\omega_{1}$ and $\omega_{2}$ is equal to one, where $\omega$ is the angular velocity.
In the solution process for optimal FACTS device allocation process, GA, coupled with the full AC power flow, which is used to determine the objective functions, selects the best solutions to minimise the voltage deviation, and real power loss within the stability constraints.

\subsection{Simulations of the Power System}

The power system is modelled in PSSE and MATPOWER. Simulations are conducted to determine the problems impacting on the stability of the power system. The simulation method used is power or load flow studies of the power system during weekday off-peak and weekday peak condition under normal system condition referred to as base-case, and single contingency (N-1) system operating condition. The contingency, $(\mathrm{N}-1)$ condition, is considered as the system state when a single power system element has been taken out of service due to scheduled or forced outage with all the remaining facilities in service.

Load flow study of the power system is the steady state solution of the power system network. Load flow study is the analysis of the power system in terms of power flow, active, and reactive power, on various lines and the voltage magnitudes and respective angles at various buses at a particular time instant for a given condition of generation and loads. The power system base for the load flow simulations is 100 MVA. There are three methods commonly used in PSSE and MATPOWER and they are: Gauss-Seidel method, Newton - Raphson method, and Fast Decupled method. All of these methods use the non-linear algebraic equations for the power flow analysis. The Newton - Raphson (NR) method is selected for the simulation because of its quadratic convergence. Newton's method is mathematically superior to the Gauss-Seidel method, and is less prone to divergence. The NR load flow method is used in this work to determine the transmission line loadings, substation bus voltages and angles, and losses across the transmission network. The key transmission system constraints are also identified during the simulations.

\subsubsection{PSSE Simulations during Weekday Off-Peak and Peak Conditions}

To evaluate the stability of the power system under steady state during weekday off-peak condition, the following PSSE simulations were conducted:

i. Base Case with all transmission lines in service;

ii. Base Case with (N-1) contingency, $330 \mathrm{kV}$ Aboadze Volta transmission line out of service;

iii. Base Case with (N-1) contingency, $161 \mathrm{kV}$ Aboadze Prestea transmission line out of service; and

iv. Base Case with 5\% increase of load demand.

The following simulations were also conducted during weekday peak condition to assess the stability of the power system under normal condition and $\mathrm{N}-1$ contingency:

i. Base Case with all transmission lines in service;

ii. Base Case with (N-1) contingency, $330 \mathrm{kV}$ Aboadze Volta transmission line out of service;

iii. Base Case with (N-1) contingency, $161 \mathrm{kV}$ Aboadze - 
Takoradi transmission line out of service; and

iv. Base Case with no generation from Aboadze generating station, i.e. all generators from TICO, TAPCO and T3 are taken out of service for the simulations.

\subsubsection{MATPOWER Simulations}

The MATPOWER simulations were conducted only for two cases with and without FACTS devices for the weekday off-peak base case and $330 \mathrm{kV}$ transmission line contingency to validate the PSSE power flow results. The FACTS devices models are incorporated into the power flow analysis, which is coupled with GA for the optimal FACTS devices allocation in the power system. All the other cases for the week day off-peak and weekday peak condition did not converge in MATPOWER and the reasons will be explained during the analysis of the simulation results in. In MATPOWER, continuation power flow (CPF) was also carried out for the weekday off-peak base case and $330 \mathrm{kV}$ transmission line contingency to compute the steady state stability of the power system. With the help of CPF analysis, the weakest bus in the power system is determined, and the PV curve is drawn, which provides crucial information concerning, for instance, voltage stability and loadability limits, at steady-state conditions of the power system.

\section{Results and Discussion}

\subsection{Weekday Off-Peak PSSE Simulation Results and Analysis}

The base case power system for the simulation is made up four areas: GRIDCo, CIE, CEB, and SONABEL, of which the interconnected network constitutes 199 buses, 268 transmission lines, 81 transformers, 52 generators, and 98 load centres. The base case generation and load details of the four areas is shown in Table 5.

Table 5. The Base Case Generation and Load Details of the Interconnected Power System for Four Areas.

\begin{tabular}{|c|c|c|c|c|c|}
\hline AREA & GENEI & & LOAD & & DESIRED NET INTERCHANGE \\
\hline GRIDCo (1) & 1779.4 & 559.6 & 1609.7 & 867.3 & 90 \\
\hline CIE (2) & 769.2 & 275.8 & 746.0 & 328.0 & 0 \\
\hline CEB (3) & 35.5 & 10.5 & 122.0 & 55.0 & -90 \\
\hline SONABEL (4) & 150.6 & 57.0 & 155.0 & 75.0 & 0 \\
\hline TOTALS & 2734.7 & 902.9 & 2632.7 & 1325.3 & 0 \\
\hline
\end{tabular}

The total generation of active and reactive power is 2734.7 MW, and 902.9 MVAr respectively, of which the power system constitutes $65 \%$ of the total generation. There is a net interchange of $90 \mathrm{MW}$ between Ghana (GRIDCo) and Togo (CEB). The difference between the generation and load represents the power loss across the interconnected transmission network.

The stability and security of the power system analysis is based on the voltage profile of substation buses, transmission line loadings, and the loss across the transmission network; and these must be within the stability constraints imposed on the system. The following sections present the results and analysis of the simulations performed.

\subsubsection{Base Case with $330 \mathrm{kV}$ Aboadze to Volta Line Out of Service}

The single contingency $(\mathrm{N}-1)$ case analyses the system steady state stability, with the $330 \mathrm{kV}$ Aboadze-Volta line out of service. Compared with the base case, the active power generation, and load, are the same but there is an increase of reactive power generation from the base case value of 903 MVAr to 948.5 MVAr. The increase is as a result of the contingency. The voltage profile for the 199 buses, transmission line loadings, and the transmission loss profile are presented in Figures 8 (a) and (b) respectively. The total active and reactive power loss is 102.1 MW and 705.9 MVAr respectively. The voltage profile, transmission line loading, and losses are almost the same as the base case.

The graphical result of the transmission line loading is shown in Figure 9. The impact of the $330 \mathrm{kV}$ transmission line on system stability is related to the reactive power compensation, which is needed to maintain the voltage stability.

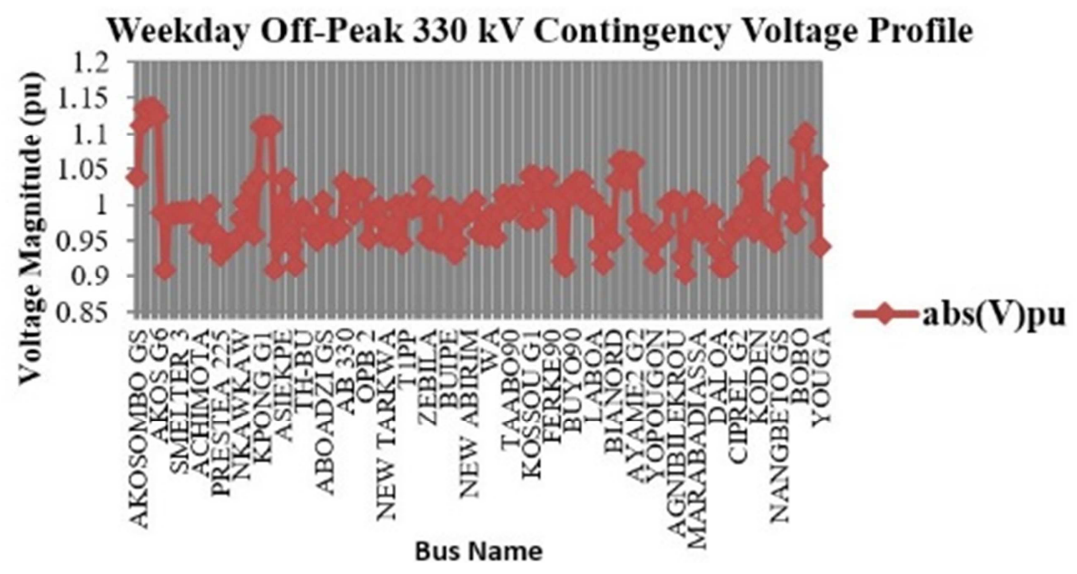




\section{Weekday Off-Peak $330 \mathrm{kV}$ Contingency Transmission Lines \% MVA Loading}

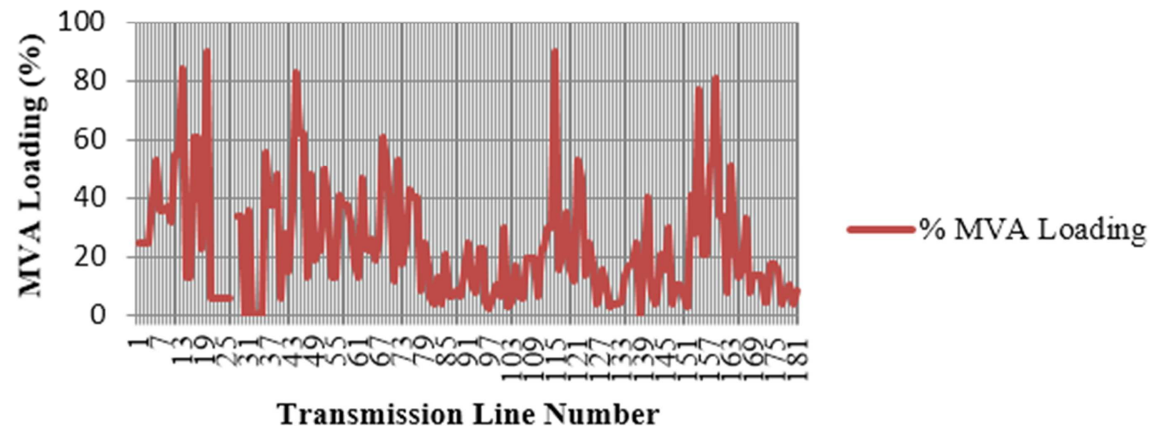

(b)

Figure 8. (a) Voltage Profile of Base Case with $330 \mathrm{kV}$ Transmission Line Out of Service; and (b) transmission Line Loading of Base Case with $330 \mathrm{kV}$ Transmission Line Out of Service

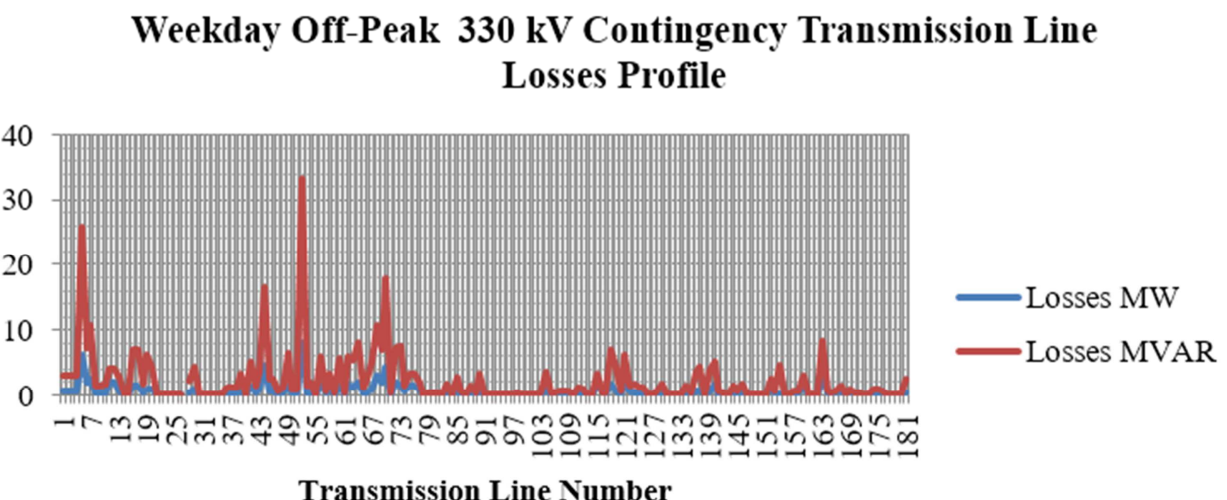

Figure 9. Transmission Line Loss Profile of Base Case with 330 kV Transmission Line Out of Service.

\subsubsection{Base Case with $161 \mathrm{kV}$ Aboadze to Prestea Line Out of Service}

The steady state stability of the power system, was assessed with single contingency $(\mathrm{N}-1)$ of the $161 \mathrm{kV}$ Aboadze to Prestea transmission line out of service due to forced outage.
During this contingency case, the system became unstable with very low voltages recorded throughout the system, leading to voltage collapse. The voltage profile for this contingency is shown in Figure 10 (a) and the transmission line loading in Figure 10 (b).

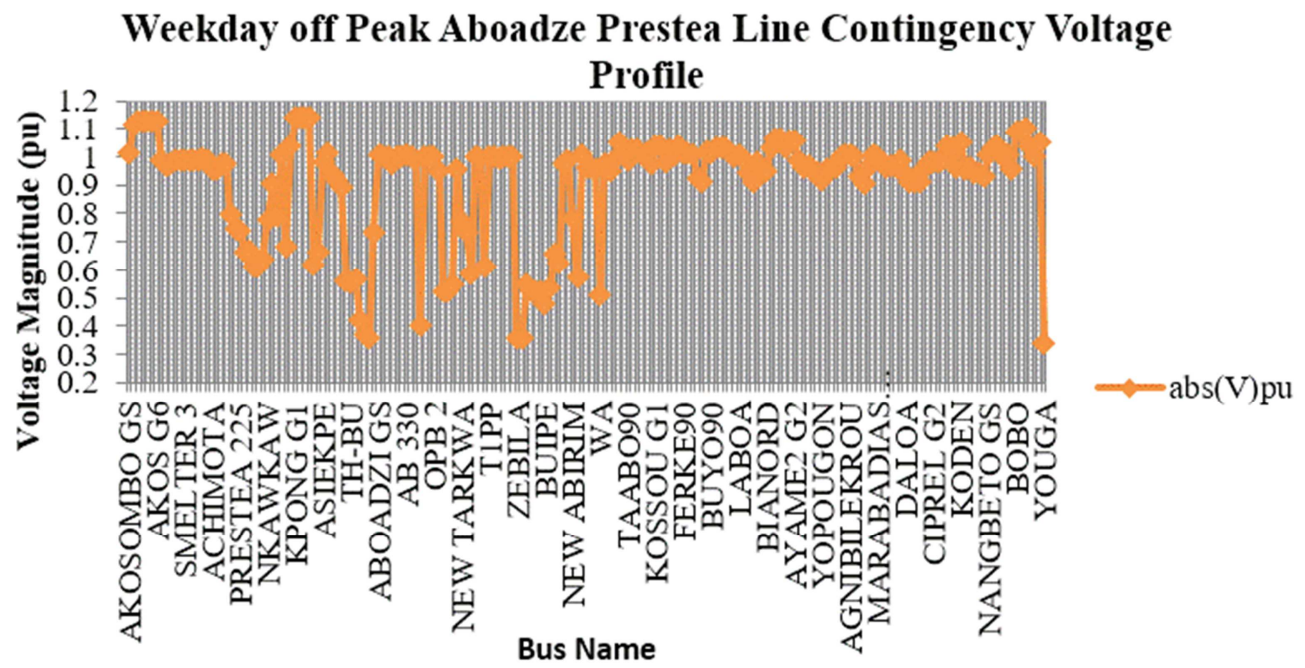

(a) 
Weekday Off-Peak Aboadze to Prestea Line Contingency Transmission Lines \% MVA Loading

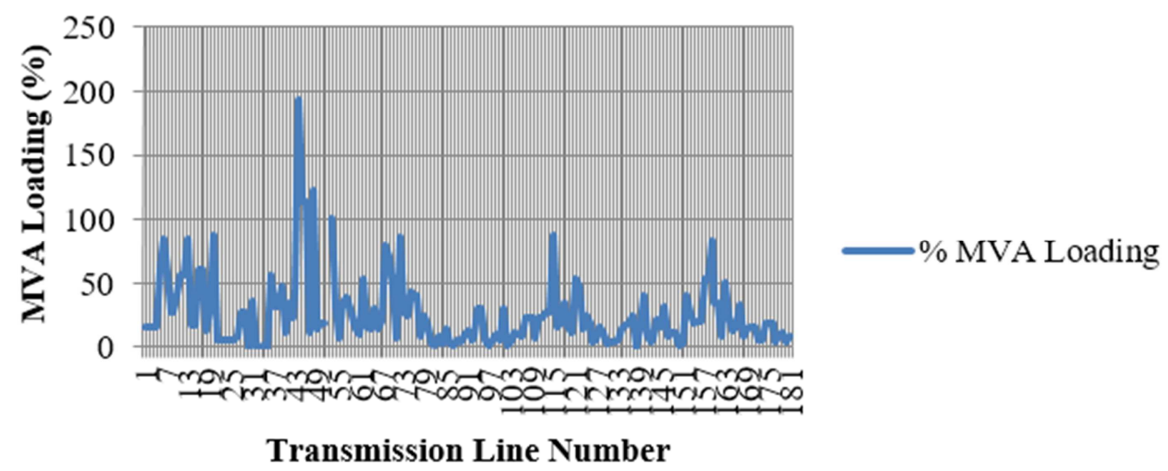

(b)

Figure 10. (a) Voltage Profile of Base Case with $161 \mathrm{kV}$ Aboadze to Prestea Transmission Line out of Service; and (b) transmission Line Loading of Base Case with $161 \mathrm{kV}$ Aboadze to Prestea Line Out of Service

From the voltage profile graph, very low voltages of less than $0.7 \mathrm{pu}$ were experienced in the Western, Kumasi and its environs and towards the north. The voltage magnitudes were very severe in the North, and the buses with less than $0.4 \mathrm{pu}$ voltage magnitude, were noted in Youga (0.3413 pu), Bawku $(0.3557 \mathrm{pu})$, Zebila $(0.3576 \mathrm{pu})$, and Bolga $(0.3685 \mathrm{pu})$. The profile of the system losses under this contingency is presented in Figure 11.

\section{Weekday Off-Peak Aboadze to Prestea line Contingency Transmission Line Losses Profile}

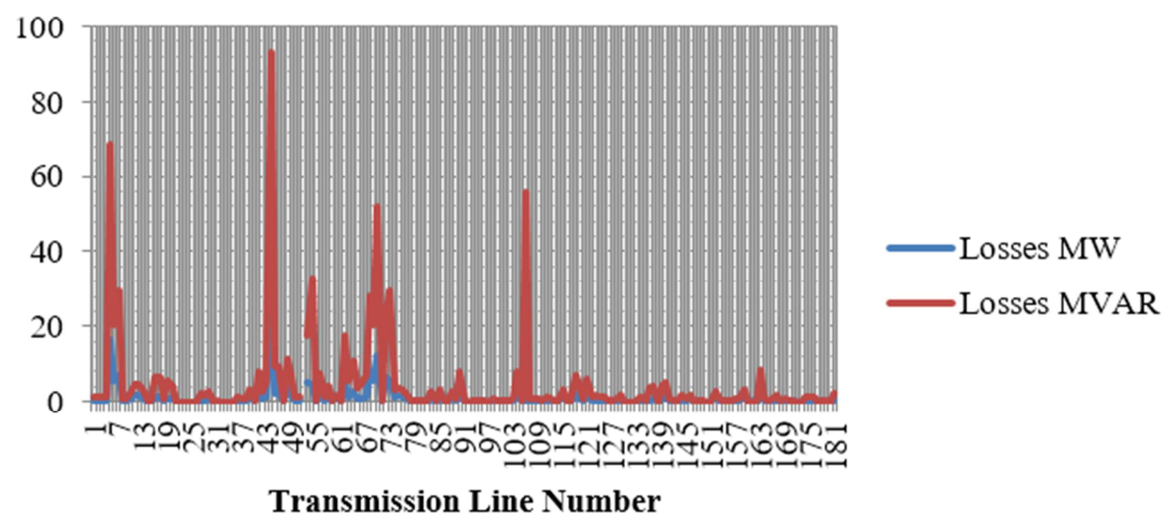

Figure 11. Transmission Loss Profile of Base Case with 161 kV Aboadze to Prestea Line out of Service.

\subsection{Weekday Peak PSSE Simulation Results and Analysis}

The power system peak period is estimated to cover a four-hour period starting from $6 \mathrm{p}$. m. to about $10 \mathrm{p}$. m. The power system steady state stability is evaluated under the peak base condition and contingency (N-1) to analyse the state of the system. The total active, and reactive power generation of the peak base case for the four areas under study is 2822.2 MW and 1007.3 MW as against an active and reactive load demand of 2734.1 MW and 1349 MVAr respectively. The power system active, and reactive power generation is 1886 MW and 641.7 MVAr and active power and reactive power load demand is $1720.1 \mathrm{MW}$ and $896 \mathrm{MVAr}$ respectively. Figure 12 (a) and (b) compares the weekday off-peak and peak base case power generation, and load of the power system. The only difference between the peak and off-peak base case is one generator is put in service at Bui generating station to provide additional generation of $100 \mathrm{MW}$ to cater for the peak demand.

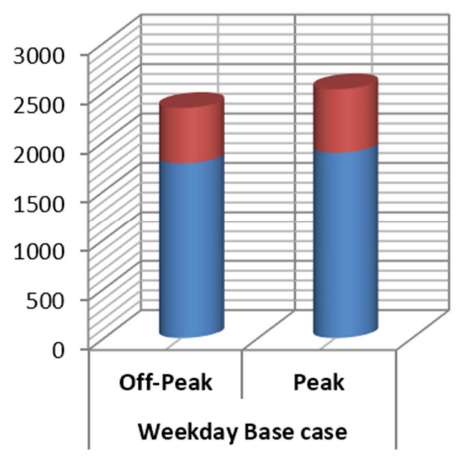

- Reactive Power Generation (MVAr)

Active Power Generation (MW) 


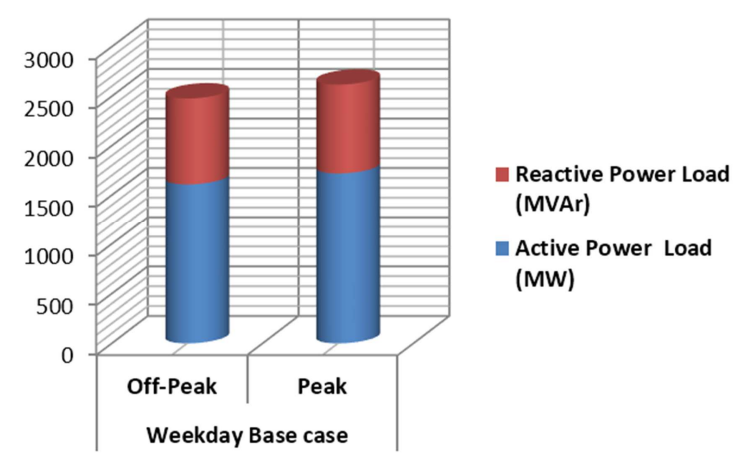

(b)

Figure 12. (a) Comparing Weekday Off-Peak and Peak Base Case Power Generation; and (b) Comparing Weekday Off-Peak and Peak Base Case Load Demand.

\subsection{Weekday Off-Peak MATPOWER Simulation Results and Analysis}

The load flow simulations in MATPOWER revealed that, due to the problems of low system voltages and overload of some transmission lines, most of the off-peak contingencies and all peak cases did not converge

during the simulations. The off-peak cases that converged in MATPOWER, are the base case with $330 \mathrm{kV}$ transmission line contingency. The PSSE load flow results signified that, the voltage profile of most buses of the base case are in violation of the voltage stability constraints. The MATPOWER converged cases which were used to validate the PSSE results for the base, and the $330 \mathrm{kV}$ line contingency cases. It also integrates with the MATLAB GA for optimal FACTS device placement in the power system to improve the voltage stability, reduce transmission losses, and congestion. The MATPOWER load flow simulations was done firstly without FACTS devices, to identify the candidate buses that need reactive power compensation, and secondly, with FACTS devices for the potential improvement of the power system voltage stability.

\subsubsection{Base Case MATPOWER Simulations without FACTS Devices}

The MATPOWER base case system, and results summary are shown in Tables 6 and 7.

The generation of actual and active power, and reactive power of 2743.3 MW and 1052.1 MVAr as against the active and reactive power load of 2632.7 MW and 1325.3 MVAr respectively are the same for PSSE. This indicates that, the data conversion from PSSE to MATPOWER was successful.

Table 6. MATPOWER Power Flow Results Summary Indicating Minimum and Maximum of Solution Parameter.

\begin{tabular}{lll}
\hline Power Flow Solution Parameter & Minimum & Maximum \\
\hline Voltage Magnitude & 0.8210 pu @ bus 4030 & 1.112 pu @ bus 1011 \\
Voltage Angle & -78.47 deg. @ bus 4031 & 2.30 deg. @ bus 1192 \\
P Losses (I^2*R) & - & 8.85 MW @line 1100-1320 \\
Q Losses (I^2*X) & - & 37.16 MVAr @line 1100-1321 \\
\hline
\end{tabular}

Table 7. MATPOWER Base Case System Results Summary of the Generation and Load Details of the Interconnected Power System.

\begin{tabular}{lllll}
\hline MATPOWER SYSTEM SUMMARY & & P (MW) & Q (MVAr) \\
\hline How Many & & How Much & 4289.0 & -1091.0 to 2460.0 \\
\hline Buses & 199 & Total Generation Capacity & 3583.0 & -834.0 to 2116.0 \\
Generators & 57 & On-line Capacity & 2743.4 & 1052.1 \\
Committed Generators & 45 & Generation (Actual) & 2632.7 & 1325.3 \\
Loads & 97 & Load & 0.0 & 361.0 \\
Shunts & 29 & Shunt (Inj.) & 110.7 & 764.7 \\
Branches & 268 & Losses (I^2*Z) & 95.3 & 676.9 \\
Transformers & 87 & Branch Charging (Inj.) & 55.1 \\
Inter-ties & 5 & Total Inter-tie Flow & \\
Areas & 4 & & \\
\hline
\end{tabular}

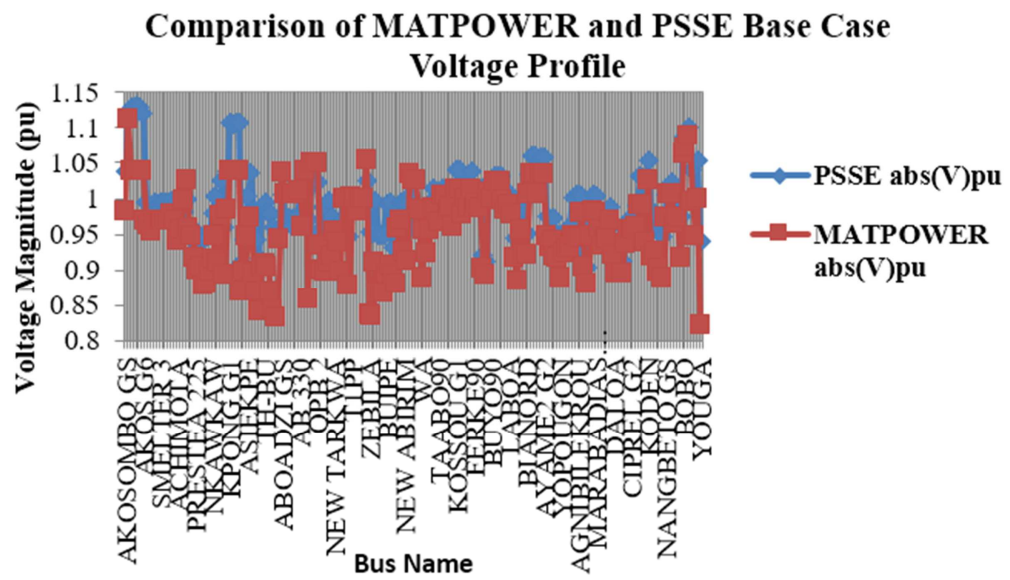

(a) 


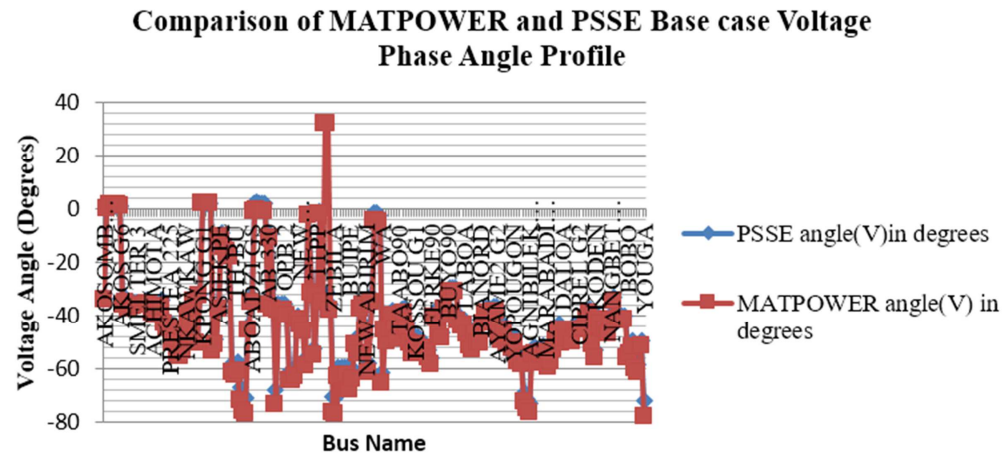

(b)

Figure 13. (a) Comparison of MATPOWER and PSSE Base Case Voltage Profile; and (b) Comparison of MATPOWER and PSSE Base Case Voltage Phase Angles Profile.

The MATPOWER base case voltage profile was compared with the PSSE base case and MATPOWER average voltage deviation of $3.4 \%$ was identified with PSSE. Considering that PSSE is a commercial software as compared to MATPOWER, the voltage deviation is within the allowable tolerance of $\pm 5 \%$ margin of error. Figure 13 (a) shows the comparison of MATPOWER and PSSE base case voltage profile. The voltage magnitude phase angles of the base case with MATPOWER and PSSE are also compared. Figure 13 (b) illustrates the comparison of the MATPOWER and PSSE base case voltage phase angles.

Comparison of Active Power Loss of Base Case MATPOWER and PSSE

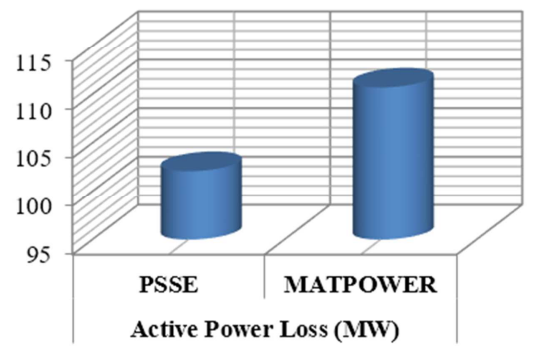

active Power Loss

(a)

Comparison of Reactive Power Loss of Base Case MATPOWER and PSSE

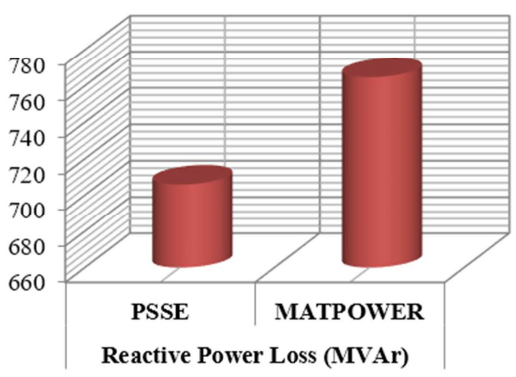

(b)

Figure 14. (a) Comparison of MATPOWER and PSSE Base Case Transmission Lines Active Power Loss; and (b) Comparison of MATPOWER and PSSE Base Case Transmission Lines Reactive Power Loss.
The MATPOWER simulation total transmission line active and reactive power loss is 110.7 MW and 764.71 MVAr respectively. The active and reactive power loss deviation of MATPOWER to PSSE is 8.6 MW and 58.8 MVAr respectively. Figures 14 (a) and (b) highlight the comparison of the active power and reactive power loss respectively. The maximum active and reactive power losses of 8.85 MW and 37.16 MVAr respectively occurs in the Prestea to Aboadze line, corresponding to the the same magnitude and transmission line as in PSSE simulations. The minimum voltage magnitude of $0.821 \mathrm{pu}$ in the power system is recorded at Youga in SONABEL area.

\subsubsection{Base Case MATPOWER Simulations with FACTS Devices}

The voltage stability of the base case is evaluated by incorporating FACTS devices in the power system by using MATPOWER load flow analysis and the GA code. The real coded genetic algorithm method was implemented and MATLAB 7.14 (2012A) was used to write the GA code.

Five (5) FACTS devices were selected for the optimal allocation and they are one (1) STATCOM, and four (4) SVC. The location, type and rating of the FACTS devices as specified by GA are presented in Table 8 . The MATPOWER system and results summary are shown in Tables 9 and 10. The voltage profile with the incorporation of the FACTS devices is compared with the base case without FACTS devices, and the comparison is presented in Figure 15 (a). From the graph, voltage stability has improved with the incorporation of the FACTS devices and the bus voltages are very close to the nominal value of $1 \mathrm{pu}$.

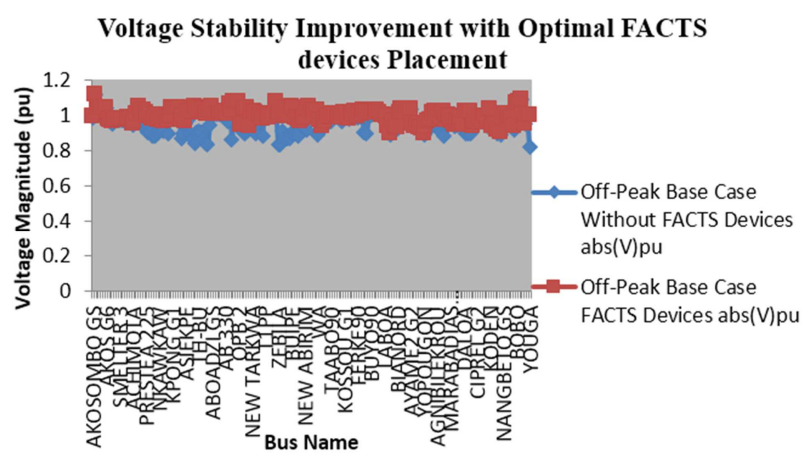

(a) 


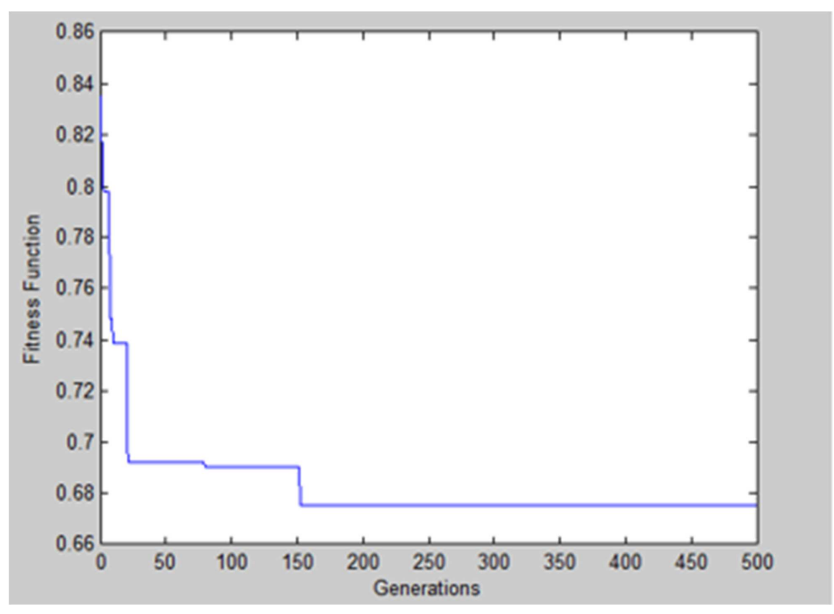

(b)

Figure 15. (a) Voltage Stability Improvement of Base Case with Optimal FACTS Devices Placement; and (b) GA Convergence Characteristic.
Table 8. Location, Type of FACTS Devices and Rating as Specified by GA.

\begin{tabular}{lllll}
\hline $\begin{array}{l}\text { Bus } \\
\text { Number }\end{array}$ & Bus Name & Location & $\begin{array}{l}\text { Type of } \\
\text { FACTS }\end{array}$ & $\begin{array}{l}\text { Rating } \\
\text { (MVAr) }\end{array}$ \\
\hline 1101 & PRESTEA 225 & 25 & STATCOM & -134.6448 \\
1200 & ASAWINSO & 41 & SVC & -5.1461 \\
1250 & KPANDU & 47 & SVC & -17.0394 \\
2080 & SAN PEDRO & 124 & SVC & -14.9934 \\
2320 & GAGNOA & 160 & SVC & -24.7257 \\
\hline
\end{tabular}

The power system stability improvement provided by the optimal FACTS devices placement using GA is provided in Table 11. The total transmission system losses for both active, and reactive power are reduced by $6.8 \%$ and $5.4 \%$ respectively. The deviation in voltage from their nominal values also reduced to almost zero. The bus voltages are closer to their nominal values of $1 \mathrm{pu}$ and the voltage stability of the power system improved.

Table 9. MATPOWER System Summary of Base Case with FACTS Devices.

\begin{tabular}{lllll}
\hline MATPOWER SYSTEM SUMMARY & & & P (MW) \\
\hline How Many & & How Much & 4289.0 & Q (MVAr) \\
\hline Buses & 199 & Total Generation Capacity & 3583.0 & -1091.0 to 2460.0 \\
Generators & 57 & On-line Capacity & 2735.9 & -834.0 to 2116.0 \\
Committed Generators & 45 & Generation (Actual) & 2632.7 & 697.8 \\
Loads & 99 & Load & 0.0 & 1121.8 \\
Shunts & 29 & Shunt (Inj.) & 103.2 & 409.9 \\
Branches & 267 & Losses (I^2*Z) & & 723.2 \\
Transformers & 87 & Branch Charging (Inj.) & 94.4 & 737.3 \\
Inter-ties & 5 & Total Inter-tie Flow & & 54.0 \\
Areas & 4 & & & \\
\hline
\end{tabular}

Table 10. MATPOWER Results Summary of Base Case with FACTS Devices.

\begin{tabular}{lll}
\hline Power Flow Solution Parameter & Minimum & Maximum \\
\hline Voltage Magnitude & 0.897 pu @ bus 2130 & 1.112 pu @ bus 1011 \\
Voltage Angle & -73.77 deg. @ bus 2290 & 2.62 deg. @ bus 1192 \\
P Losses $\left(I^{\wedge} 2 * R\right)$ & - & 7.84 MW @line 1100-1320 \\
Q Losses $\left(I^{\wedge} 2 * X\right)$ & - & 32.93 MVAr@line 1100-1321 \\
\hline
\end{tabular}

Table 11. Improvements by GA.

\begin{tabular}{|c|c|c|c|}
\hline & & Before FACTS Placement & After FACTS Placement \\
\hline $\begin{array}{l}\text { Total Transmission Losses } \\
\text { Average Voltage Deviation }\end{array}$ & $\begin{array}{l}\text { Active } \\
\text { Reactive }\end{array}$ & $\begin{array}{l}110.7000 \mathrm{MW} \\
764.7100 \mathrm{MVAr} \\
0.0418\end{array}$ & $\begin{array}{l}103.2150 \mathrm{MW} \\
723.2100 \mathrm{MVAr} \\
0.0087\end{array}$ \\
\hline
\end{tabular}

The convergence characteristic of GA for the base case optimal FACTS device placement is shown in Figure 15 (b). The algorithm was found to converge to a global optimum after about 150 generations and with an average computational time of about 7 hours.

\section{Conclusions}

The power system has been modelled under steady state using PSSE. The load flow simulations with Newton-Raphson method of the weekday off-peak and peak base case with and without contingencies, were carried out to assess the steady state stability of the power system. The PSSE weekday off-peak base case, and 330 line contingency simulation results were validated using MATPOWER and the validation indicates that, MATPOWER simulation results are within a deviation error of $\pm 5 \%$. From the results, the following conclusions are drawn:

i. Inadequacy in the transmission line capacity results in transmission line overloads at the Volta to Accra East and Achimota to Mallam transmission lines;

ii. Inadequate reactive power compensation is a problem facing the power system and this leads to voltage instability;

iii. For the simulated (N-1) contingencies, high reactive power loss was also identified and this resulted in bus voltages in the Western corridor towards Kumasi and its environs and the Northern corridor violating the minimum voltage stability constraints of $0.95 \mathrm{pu}$;

iv. The effect of $330 \mathrm{kV}$ Volta to Aboadze transmission 
line contingency results in high reactive power generation from Aboadze to maintain voltage stability;

v. The power system loadability evaluated in MATPOWER using the continuation power flow identified the Achimota substation was the weakest bus, vulnerable to voltage collapse above the maximum loadability factor of 0.9053 of base case;

vi. GA as artificial intelligence-based method was used to optimally size and locate five (5) FACTS devices; one (1) STATCOM and four (4) SVC in the power system; and

vii. The use of MATPOWER within MATLAB 2012A software allowed the incorporation of load flow analysis, thereby reducing the complexity of the GA algorithm.

\section{Recommendations}

Based on the results and findings of this study, the following recommendations are made:

i. Transmission capacity be increased from Volta to Accra East, Volta to SMD, Aboadze to Prestea, and Achimota to Mallam transmission lines to prevent overloads/congestion during the peak period and contingencies;

ii. The Aboadze generation plant be upgraded to ensure constant generation onto the national grid as this improves significantly the power system stability, even when the $330 \mathrm{kV}$ Volta to Aboadze line is under contingency;

iii. The highest active and reactive power loss recorded on the Aboadze to Prestea line can be reduced by the installation of series compensation such as TCSC with rating $-0.4 \mathrm{XL}$; and

iv. FACTS devices such as STATCOM, SVC and TCSC must be used to improve voltage stability and transmission line losses.

\section{References}

[1] Kundur, P.; Paserba, J.; Ajjarapu, V.; Andersson, G.; Bose, A.; Canizares, C.; Hatziargyriou, N.; Hill, D.; Stankovic, A.; Taylor, C.; Van Cutsem, T. and Vittal, V. (2004) "Definition and classification of power system stability IEEE/CIGRE joint task force on stability terms and definitions," IEEE Transactions on Power Systems, Vol. 19, No. 3, pp. 1387-1401.

[2] Savulescu, S. C. (2009), "Real-Time Stability Assessment in Modern Power System Control Centers", pp 413, John Wiley and Sons, Inc., Hoboken, New Jersey, ISBN 978-0470-23330-6.

[3] Hou, K., Shao, G., Wang, H. (2018). Research on practical power system stability analysis algorithm based on modified SVM. Prot Control Mod Power Syst 3, 11. https://doi.org/10.1186/s41601-018-0086-0.

[4] Iyambo, P. K., Tzoneva, R. (2007), "Transient stability analysis of the IEEE 14-bus electric power system," AFRICON, pp. 1-9.

[5] Abdelaziz, A. Y., Ibrahim, A. M. and Hasan, Z. G. (2013), "Transient stability analysis with equal-area criterion for out of step detection using phasor measurement units", International
Journal of Engineering, Science and Technology, Vol. 5, No. 1, pp. 1-17.

[6] ONI, Oluwafemi Emmanuel; MBANGULA, Kamati I.; DAVIDSON, Innocent E. (2016). Dynamic Voltage Stability Studies using a Modified IEEE 30-Bus System. Transactions on Environment and Electrical Engineering, [S.1.], v. 1, n. 3, pp. 41-49, ISSN 2450-5730.

[7] Hasani, M. and Parniani, M. (2005), "Method of Combined Static and Dynamic Analysis of Voltage Collapse in Voltage Stability Assessment," IEEE/PES Transmission and Distribution Conference and Exhibition: Asia and Pacific, pp. 1-6.

[8] Acha, E., Fuerte, C. R., Pe'rez, H. A. and Camacho, C. A. (2004), "FACTS Modelling and Simulation in Power Networks", pp. 9-12, John Wiley \& Sons Ltd, West Sussex.

[9] Hingorani, N. G. and Gyugyi, L. (2000), “UNDERSTANDING FACTS: Concept and Technology of Flexible AC Transmission Systems" Wiley- IEEE Press, 452pp.

[10] Suman Bhowmick (2018), "Flexible AC Transmission Systems (FACTS): Newton Power-Flow Modeling of Voltage-Sourced Converter-Based Controllers", pp 291, CRC Press, ISBN 1498756212,9781498756211

[11] Uzochukwuamaka Okeke, T. and Zaher, R. G. (2013), "Flexible AC Transmission Systems (FACTS)", International Conference on New Concepts in Smart Cities: Fostering Public and Private Alliances (SmartMILE), pp. 1-4.

[12] Ghahremani, E. and Kamwa, I. (2013), "Optimal placement of multiple-type FACTS devices to maximize power system loadability using a generic graphical user interface" IEEE Transactions on Power Systems, Vol. 28, No. 2, pp. 764-778.

[13] Ghahremani, E. and Kamwa, I. (2014), "Analysing the effects of different types of FACTS devices on the steady-state performance of the Hydro-Québec network", IET Generation, Transmission \& Distribution, Vol. 8, No. 2, pp. 233-249.

[14] Sirjani, R., Mohamed, A. and Shareef, H. (2013), "Comparative study of effectiveness of different VAR compensation devices in large-scale power networks", Journal of Central South University, Vol. 20, No. 3, pp. 715-723.

[15] Mahdad, B., Bouktir, T. and Srairi, K. (2007), "Methodology Based in Practical Fuzzy Rules Coordinated with Asymmetric Dynamic Compensation Applied to the Unbalanced Distribution Network", International Review of Electrical Engineering (IREE), Vol. 3, No. 2, pp. 145-153.

[16] Galloway, S. J., Elders, I. M., Burt, G. M. and Sookananta, B. (2009), "Optimal flexible alternative current transmission system device allocation under system fluctuations due to demand and renewable generation," IET Generation, Transmission \& Distribution, Vol. 4, No. 6, pp. 725-735.

[17] Sookananta, B., Galloway, S., Burt, Graeme M. and McDonald, J. R. (2006), "The Placement of Facts Devices in Modern Electrical Network", Proceedings of the 41st International Universities Power Engineering Conference, Vol. 2, No., pp. 780-784.

[18] Hussain, M. H., Musirin, I. Rahim, S. R. A., Abidin, A. F. (2013), "Computational Intelligence Based Technique in Optimal Overcurrent Relay Coordination: A Review", The International Journal of Engineering and Science (IJES), Vol. 2, No. 1, pp. 1-9. 
[19] Aghaei, J., Gitizadeh, M. and Kaji, M. (2012), "Placement and Operation Strategy of FACTS Devices using optimal continuous power flow", Scientia Iranica Transactions D: Computer Science \&Engineering and Electrical Engineering, Vol. 19, No. 6, pp. 1683-1690.
[20] Zimmerman, R. D., Murillo-Sánchez, C. E. and Thomas, R. J. (2011), "MATPOWER: Steady-State Operations, Planning and Analysis Tools for Power Systems Research and Education", IEEE Transactions on Power Systems, Vol. 26, No. 1, pp. 12-19. 